\section{Erratum}

https://doi.org/10.11646/zootaxa.5020.3.9

http://zoobank.org/urn:1sid:zoobank.org:pub:63E22AE0-0835-4EFF-B223-F0C4D6D1262E

\title{
GUILHERME SICHIERI, CARLOS ALBERTO GONÇALVES CRUZ, BRUNO V.S. PIMENTA \& IVAN NUNES (2021) Advertisement call description of two Proceratophrys species
} (Anura: Odontophrynidae). Zootaxa, 4975: 397-400.

On page 399, acknowledgments section one of the authors (GS) forgot to acknowledge one of the institutions that financially supported our work. The correction desired is assigned in bold and underlined.

Previous version: We thank José Eduardo Simon (In memorian), from MBML and Faculdades Integradas São Pedro (FAESA), for the partnership with the initial study design and calls loan. GS acknowledges Coordenação de Aperfeiçoamento de Pessoal de Nível Superior (CAPES) for the Master Degree Scholarship. CAGC is grateful to Conselho Nacional de Desenvolvimento Científico e Tecnológico (CNPq) for Research Productivity Grant. IN acknowledges PROPe/UNESP for the support (Primeiros Projetos \#822, Ivan Nunes Principal Investigator).

Corrected version: We thank José Eduardo Simon (In memorian), from MBML and Faculdades Integradas São Pedro (FAESA), for the partnership with the initial study design and calls loan. GS acknowledges Coordenação de Aperfeiçoamento de Pessoal de Nível Superior (CAPES) for the Master Degree Scholarship and Fundação de Amparo à Pesquisa do Estado de São Paulo (FAPESP) for the financial support (\#2017/18951-2). CAGC is grateful to Conselho Nacional de Desenvolvimento Científico e Tecnológico (CNPq) for Research Productivity Grant. IN acknowledges PROPe/UNESP for the support (Primeiros Projetos \#822, Ivan Nunes Principal Investigator). 